\title{
Therapeutic efficacy of azaindole-1 in experimental pulmonary hypertension
}

\author{
B.K. Dahal*,+, D. Kosanovic ${ }^{*,+}$, P.K. Pamarthi* ${ }^{*}$ A. Sydykov*, Y-J. Lai*, R. Kast ${ }^{*}$, \\ H. Schirok*, J-P. Stasch\#, H.A. Ghofrani*, N. Weissmann*, F. Grimminger*, \\ W. Seeger* ${ }^{\star}$ and R.T. Schermuly*,
}

ABSTRACT: An accumulating body of evidence incriminates Rho kinase (ROCK) in the pathogenesis of pulmonary hypertension $(\mathrm{PH})$. The therapeutic efficacy of azaindole-1, a novel highly selective and orally active ROCK inhibitor, has not yet been investigated in PH.

This study aimed to investigate the effects of azaindole-1 on 1) acute hypoxic pulmonary vasoconstriction (HPV), 2) proliferation of pulmonary arterial smooth muscle cells (PASMCs) and 3) animal models of $\mathrm{PH}$.

Azaindole-1 significantly inhibited HPV in isolated, ventilated and buffer-perfused murine lungs and proliferation of primary rat PASMCs in vitro. Azaindole-1 was administered orally from 21 to 35 days after monocrotaline (MCT) injection in rats and hypoxic exposure in mice. Azaindole-1 (10 and $\mathbf{3 0} \mathrm{mg}$ per $\mathbf{k g}$ body weight per day in rats and mice, respectively) significantly improved haemodynamics and right ventricular hypertrophy. Moreover, the medial wall thickness and muscularisation of peripheral pulmonary arteries were ameliorated. Azaindole-1 treatment resulted in a decreased immunoreactivity for phospho-myosin phosphatase target subunit 1 and proliferating cell nuclear antigen in pulmonary vessels of MCT-injected rats, suggesting an impaired ROCK activity and reduced proliferating cells.

Azaindole-1 provided therapeutic benefit in experimental $\mathrm{PH}$, and this may be attributable to its potent vasorelaxant and antiproliferative effects. Azaindole-1 may offer a useful approach for treatment of $\mathrm{PH}$.

KEYWORDS: Azaindole-1, hypoxia, monocrotaline, pulmonary hypertension, Rho kinase
AFFILIATIONS

*University of Giessen Lung Center, Giessen,

\#Bayer HealthCare, Wuppertal, and - Max-Planck-Institute for Heart and Lung Research, Bad Nauheim, Germany.

${ }^{+}$Both authors contributed equally to this work.

CORRESPONDENCE

R.T. Schermuly

Max-Planck-Institute for Heart and Lung Research

Parkstrasse 1

61231 Bad Nauheim

Germany

E-mail: ralph.schermuly@

mpi-bn.mpg.de

Received:

Sept 042009

Accepted after revision:

April 212010

First published online:

June 072010
$\mathbf{P}$ ulmonary arterial hypertension (PAH) is a chronic fatal disease characterised by sustained elevation of pulmonary artery pressure and reduced exercise tolerance. As a consequence, the right ventricular afterload increases and culminates in right ventricular failure. PAH has a complex pulmonary vascular pathophysiology, including vasoconstriction, vascular remodelling and in situ thrombosis. The progressive vascular remodelling, the hallmark of PAH pathology, is attributable to abnormalities in vascular cells, such as increased proliferation and resistance to apoptosis [1-3]. However, the precise molecular mechanism is incompletely understood, and so a therapeutic approach for curing this disease is currently sought after.

The small GTPase RhoA is one of the members of the Rho protein family that regulate cellular functions such as contraction, motility, proliferation and apoptosis, and Rho kinases (ROCKs) are the best characterised downstream targets for RhoA [4]. Two isoforms of the serine/threonine kinase ROCK have been identified: ROCK-1 and ROCK-2 [5-7]. ROCKs are ubiquitously expressed in tissues including vasculature and heart. Owing to its role in key cell functions, hyperactive ROCK signalling results in cardiovascular disorders associated with sustained abnormal vasoconstriction and promotion of vascular remodelling [8, 9]. Studies on animal models of pulmonary hypertension $(\mathrm{PH})$, such as chronic hypoxia-, monocrotaline (MCT)-, vascular endothelial growth factor receptor inhibition and chronic hypoxia-, pneumonectomy and MCT- and bleomycin-induced PH suggest that increased ROCK is involved in the pathogenesis [10-16]. Moreover, data are emerging that implicate ROCK signalling in clinical PH and that ROCK inhibition provides beneficial acute effects in patients [17-23]. 
Fasudil and Y-27632 are the two most commonly investigated ROCK inhibitors [24, 25]. Fasudil has been approved for human use in Japan for the treatment of cerebral vasospasm after subarachnoid haemorrhage and is also a relatively potent inhibitor of other kinases, such as protein kinase $C[26,27]$. These inhibitors have been instrumental in elucidating the role of ROCK in the pathobiology of PH. The ROCK inhibitors show beneficial effects on rodent models of $\mathrm{PH}$; however, discrepancy in their efficacy has also been observed depending on the dose, route of administration and animal model [9]. Recently, a highly selective and orally active azaindole-based ROCK inhibitor has been reported [28, 29]. This novel ROCK inhibitor, azaindole-1, functions in an ATP-competitive manner with activity in the low nanomolar range (half maximal inhibitory concentration $\left(\mathrm{IC}_{50}\right)$ of $0.6 \mathrm{nM}$ and $1.1 \mathrm{nM}$ for human ROCK1 and ROCK2, respectively). Moreover, oral administration of azaindole-1 induces a dose-dependent decrease in blood pressure without inducing a significant reflex increase in heart rate of normotensive and spontaneously hypertensive rats [28]. However, the therapeutic potential of azaindole- 1 in animal models of $\mathrm{PH}$ has not yet been explored. In this study, we have therefore investigated the effects of azaindole- 1 on 1) acute hypoxic pulmonary vasoconstriction (HPV) in isolated, ventilated and bufferperfused murine lungs and proliferation of rat pulmonary arterial smooth muscle cells (PASMCs) in vitro, 2) haemodynamics, right ventricular hypertrophy (RVH) and pulmonary vascular remodelling in experimental $\mathrm{PH}$ induced by MCT injection in rats and by chronic hypoxic exposure in mice, and 3) ROCK activity and pulmonary vascular cell proliferation by immunohistochemistry of the lung tissues of MCT-injected rats for phospho-myosin phosphatase target subunit 1 (p-MYPT1) and proliferating cell nuclear antigen (PCNA).

\section{METHODS}

\section{Animals}

Adult male Sprague-Dawley rats (300-350 g body weight) and C57BL/6 mice (20-22 g body weight) were obtained from Charles River Laboratories, Sulzfeld, Germany. PH was induced in rats by MCT (Sigma-Aldrich, Munich, Germany) injection and in mice by exposing to chronic hypoxia (10\%), as described [30]. All studies were performed according to the guidelines of the University of Giessen, Giessen, Germany and were approved by the local authorities (Regierungs praesidium Giessen, GI20/10-Nr.48/2009; GI 20/10 Nr.39/2009).

\section{Experimental design}

Radio-telemetry study

MCT-injected rats were randomised into two groups and received either azaindole-1 (Bayer Health Care AG, Wuppertal, Germany) or placebo from day 21 for 2 weeks. Azaindole-1 was prepared daily in transcutol-based vehicle as described [28] and rats were treated by oral gavage at the dose of $10 \mathrm{mg}$ per $\mathrm{kg}$ body weight per day. The placebo group received only vehicle. The dose of azaindole-1 was selected based on literature [28] and our own pilot experiments (data not shown). The right ventricular systolic pressure (RVSP) and heart rate were monitored online with an implanted radio-telemetry system (Dataquest A.R.T. 2.1; Data Sciences Inc., St Paul, MN, USA) as described [30]. Briefly, a catheter connected to a fluidfilled sensor was inserted into the jugular vein and forwarded to the right ventricle of rats under anaesthesia. The signal from the transmitter (model TA11PA-C40; Data Sciences Inc.) was transferred to a remote receiver and a data-exchange matrix connected to a computer. The waveform was displayed on the computer and used to ensure correct positioning of the catheter. Animals were allowed to recover and were housed individually in standard rat cages. RVSP and heart rate were recorded once per day over the next 35 days from the time of MCT injection.

\section{Chronic treatment study}

To investigate the therapeutic efficacy of azaindole- 1 in animal models of $\mathrm{PH}$, chronic treatment studies were performed. The MCT-injected rats were randomised into two groups and treated orally by gavage from 21 to 35 days either with azaindole-1 (10 mg per $\mathrm{kg}$ body weight per day) or placebo. Saline-injected rats served as healthy control. Mice exposed to chronic hypoxia were treated daily with azaindole-1 (30 mg per $\mathrm{kg}$ body weight per day) or placebo from 21 to 35 days. As mentioned, the dose of azaindole- 1 was selected based on literature [28] and our own pilot experiments (data not shown) and prepared daily for oral application. Control mice remained under normoxia $\left(21 \% \mathrm{O}_{2}\right)$. At the end of the experiment (day 35 of the MCT injection in rats or chronic hypoxic exposure of mice) the animals were sacrificed for haemodynamic and $\mathrm{RVH}$ measurements.

\section{Haemodynamic and RVH measurements}

RVSP was measured by a catheter inserted into the right ventricle via the right jugular vein, and for systemic arterial pressure (SAP) the left carotid artery cannulation was performed as described [30]. Cardiac output was calculated using the Fick principle, by employing the mixed venous oxygen and the arterial oxygen content, as previously described [31]. The total pulmonary and systemic vascular resistance indexed to body weight (TPR and TSR, respectively) were determined as reported [32]. The heart was dissected to separate the right ventricle from the left ventricle plus septum, and the weight ratio of these $(\mathrm{RV} /(\mathrm{LV}+\mathrm{S}))$ was calculated as a measurement for RVH.

\section{Histology and pulmonary vascular morphometry}

Lung tissue preparation, sectioning, staining and vascular morphometry were done as described [33]. Intra-acinar arteries in rats and mice were analysed by categorising them as fully muscular, partially muscular and nonmuscular. In addition, the medial wall thickness of the vessels was analysed. All analyses were done in a blinded fashion.

\section{Immunohistochemistry for p-MYPT1 and PCNA}

Paraffin-embedded lung tissue sections with thickness of $3 \mu \mathrm{m}$ were deparaffinised in xylene and rehydrated in a graded ethanol series to PBS ( $\mathrm{pH}$ 7.4). Antigen retrieval was performed by pressure cooking in citrate buffer ( $\mathrm{pH}$ 6.0). The sections were pretreated with hydrogen peroxide $(15 \%)$ to quench endogenous peroxidase activity. Following blocking with bovine serum albumin $(10 \%)$ for $1 \mathrm{~h}$ and then with blocking serum (Impress reagent kit; Vector Laboratories, Burlingame, CA, USA) for $20 \mathrm{~min}$, the sections were incubated overnight at $4{ }^{\circ} \mathrm{C}$ with primary antibodies. Rabbit polyclonal anti-PCNA and goat polyclonal anti-p-MYPT1 (Thr 696) 
antibodies (1:100 and 1:20 dilutions, respectively; Santa Cruz Biotechnology Inc., Santa Cruz, CA, USA) were used as primary antibodies. Development of the dye was carried out with peroxidase and substrate (NovaRed substrate kit; Vector Laboratories) according to manufacturer's instruction (Vector Laboratories). Finally, sections were counterstained with haematoxylin (Zymed Laboratory, Cambridge, UK) and coverslipped using mounting medium. PCNA-positive pulmonary vascular cells were counted throughout the entire section and the index of proliferation (IOP) was determined as the number of PCNA-positive cells per pulmonary vessel. The IOP (in \%) for placebo and azaindole-1 treated groups was calculated by assuming the average IOP of healthy control lungs as $100 \%$.

\section{Isolated murine lungs}

The technique of successive hypoxic manoeuvres was employed in isolated, ventilated and buffer-perfused mice lungs to investigate the effect of azaindole-1, fasudil (H139; Sigma-Aldich) and Y-27632 (Y0503; Sigma-Aldich) on acute HPV as described [34]. The ROCK inhibitors were prepared in dimethyl sulphoxide (DMSO). Sequential hypoxic manoeuvres of $10 \mathrm{~min}$ duration interrupted by $15 \mathrm{~min}$ periods of normoxia were performed. The effect of the ROCK inhibitors on pressure responses provoked by alveolar hypoxia $\left(\begin{array}{lll}1 \% & \mathrm{O}_{2}\end{array}\right)$ was
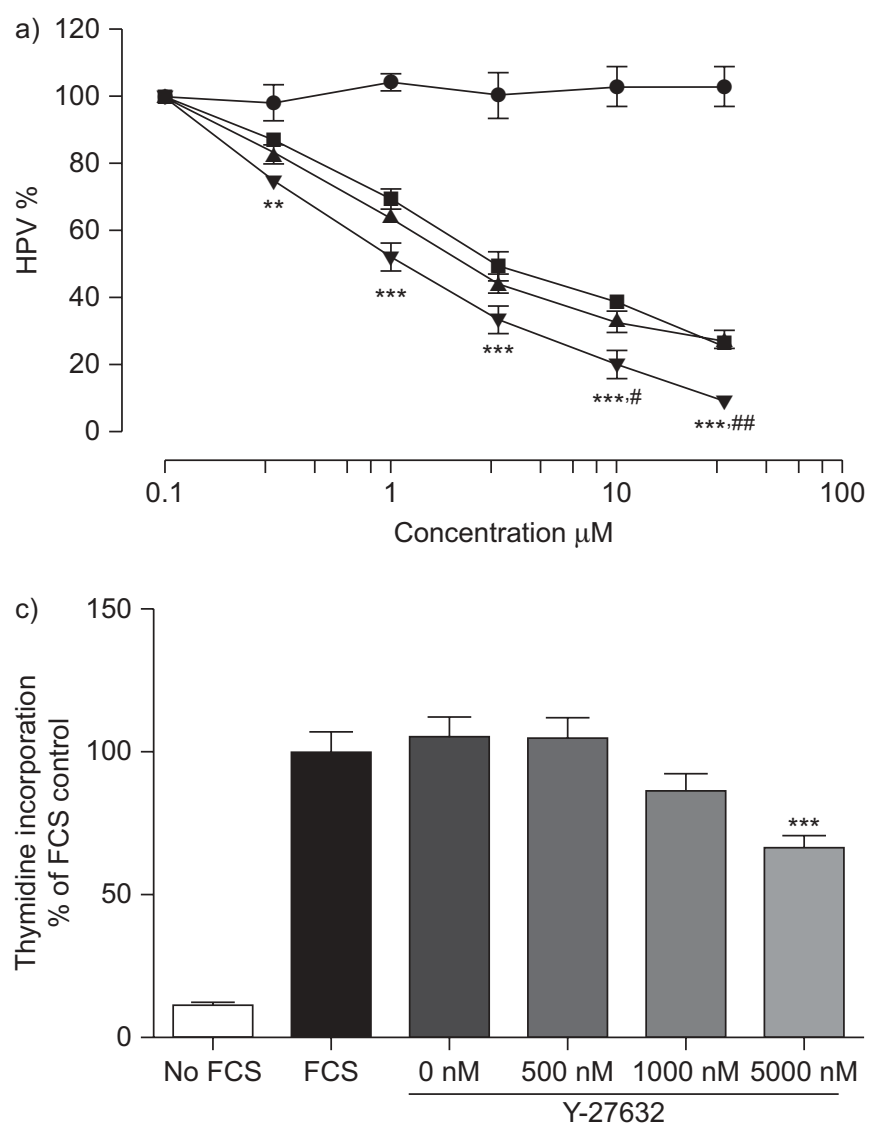

determined within such a sequence of repetitive hypoxic manoeuvres. The ROCK inhibitors were added to the buffer fluid $5 \mathrm{~min}$ after a hypoxic challenge, with the addition starting after the second hypoxic manoeuvre was accomplished. Cumulative dose-effect curves were established by addition of the inhibitors (dose range $0.1-30.0 \mu \mathrm{M}$ ). Controls received the vehicle (DMSO) only.

\section{MTT and thymidine incorporation assays}

The isolation, culture and proliferation assay of primary PASMCs was carried out as described previously [33]. Briefly, cells were isolated from healthy and MCT-injected rats (day 21, n=3) and cultures were maintained at $37^{\circ} \mathrm{C}$ in a humidified $5 \% \mathrm{CO}_{2} / 95 \% \mathrm{O}_{2}$ atmosphere. Equal numbers of PASMCs $\left(\sim 4 \times 10^{4}\right.$ cells per well $)$ were seeded and the following day the medium was substituted with DMEM/F12 containing $0.1 \%$ fetal calf serum (FCS) to render the cells quiescent. After $24 \mathrm{~h}$ serum starvation, cells were induced to cell cycle re-entry by FCS $(10 \%)$ together with different concentrations of fasudil, Y-27632 and azaindole-1 (500, 1,000 and 5,000 $\mathrm{nM}$ in DMSO) for $24 \mathrm{~h}$, including in the last $12 \mathrm{~h}$ the incorporation of ${ }^{3} \mathrm{H}$-thymidine $\left(1.5 \mu \mathrm{Ci} \cdot \mathrm{mL}^{-1}\right.$; Amersham Biosciences, Munich, Germany). Cells were then washed twice with $500 \mu \mathrm{L}$ chilled HBSS, fixed with $250 \mu \mathrm{L}$ ice-cold methanol
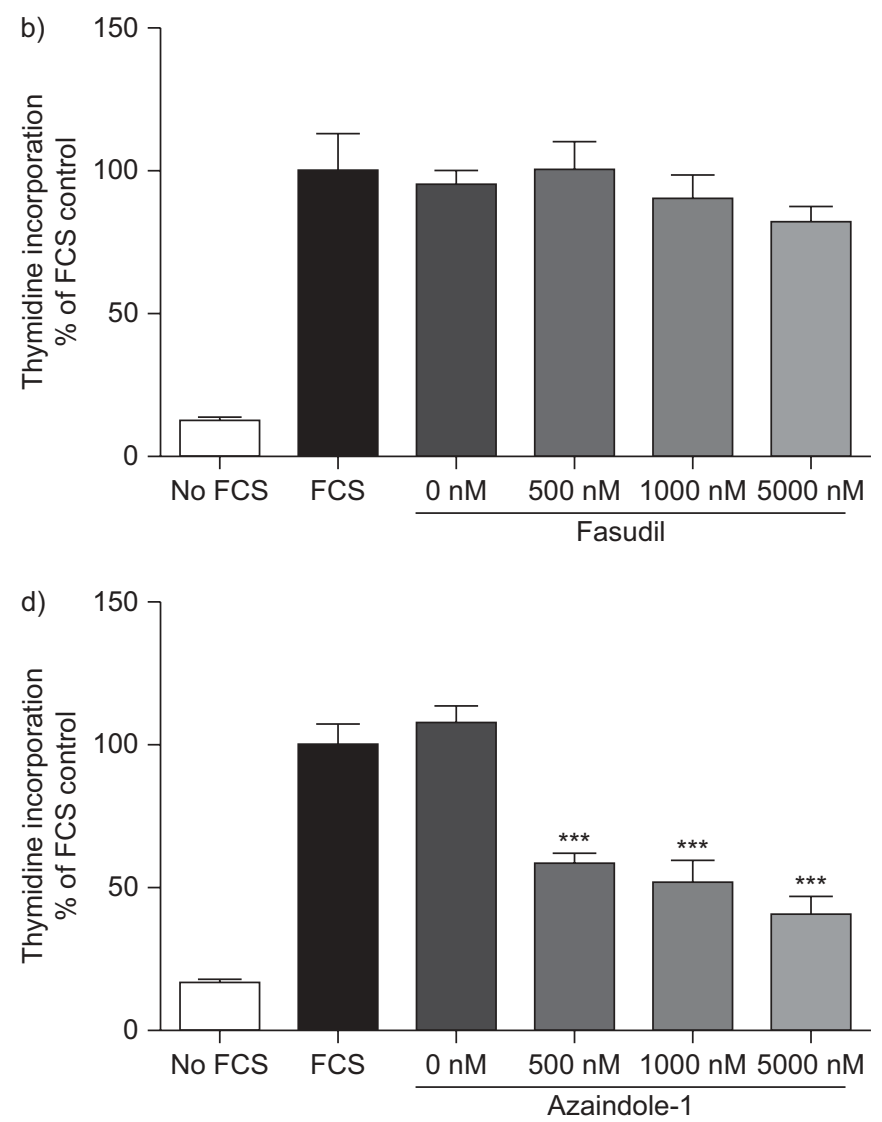

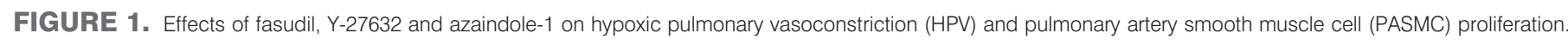

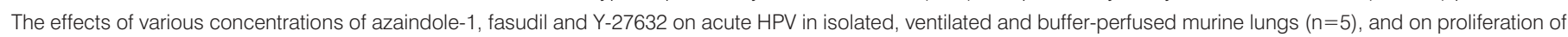

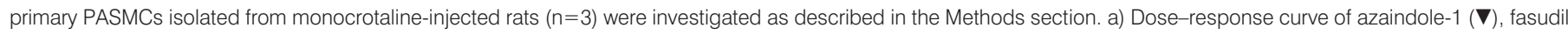

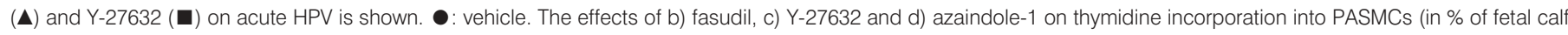

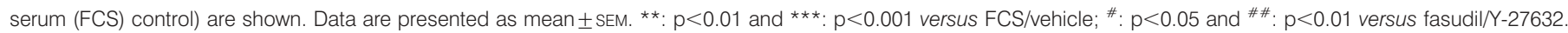


and precipitated by $250 \mu \mathrm{L} 10 \%$ trichloroacetic acid. Finally, samples were lysed in $0.1 \mathrm{M} \mathrm{NaOH}$ and transferred to $4 \mathrm{~mL}$ scintillation solution and counted by a beta-counter. The values are expressed in disintegrations per minute. All the experiments were done in triplicate.

Cell viability/cytotoxicity were assessed by the MTT assay using a CellTiter 96AQ kit (Promega, Mannheim, Germany) according to the manufacturer's instructions. Briefly, the cells were plated in 96-well plates and allowed to attach for $6 \mathrm{~h}$, and then cultured under serum-free conditions with various concentrations of fasudil, Y-27632 and azaindole- 1 for $48 \mathrm{~h}$. The number of surviving cells was determined by measuring the absorbance at $560 \mathrm{~nm}$ of the dissolved formazan product after addition of 3-(4,5-dimethylthiazol-2-yl)-5-(3-carboxymethoxyphenyl)-2-(4-sulfophenyl)-2H-tetrazolium salt for $1 \mathrm{~h}$. All of the experiments were carried out in triplicate.

\section{Data analysis}

All data are expressed as mean \pm SEM. The different experimental groups were analysed by one-way ANOVA and Newman-Keuls post hoc test for multiple comparisons. Values of $p<0.05, p<0.01$ and $p<0.001$ were considered as statistically significant. Two-way ANOVA analysis with Bonferroni multiple comparison post hoc test was performed to compare the RVSP values derived by telemetric measurement.

\section{RESULTS}

\section{Effects of azaindole-1 on acute HPV}

The pulmonary vasorelaxant potency of azaindole- 1 and the other commonly used ROCK inhibitors fasudil and Y-27632 were investigated in isolated, ventilated and buffer-perfused murine lungs. All the ROCK inhibitors significantly reduced the HPV in a dose-dependent manner $(\mathrm{p}<0.05$ versus vehicle control). The maximum inhibitory effects on HPV were $\sim 75 \%$ for fasudil and Y-27632 and $\sim 90 \%$ for azaindole-1 at the highest concentration, $30 \mu \mathrm{M}$ (fig. 1a). The effects of fasudil and Y-27632 were comparable; however, a clear leftward shift of the dose-response curve was observed with azaindole- 1 as compared with fasudil and Y-27632. At the higher doses (10 and $30 \mu \mathrm{M}$ ) there were significant reductions of HPV by azaindole- 1 versus fasudil and Y-27632. The findings suggest that azaindole- 1 is a potent pulmonary vasorelaxant.

\section{Effects of azaindole-1 on PASMC proliferation}

The effect of azaindole- 1 on PASMC proliferation was investigated by thymidine incorporation assay. In each assay, fasudil and Y-27632 were also included. There were no significant effects of various concentrations of the ROCK inhibitors (500, 1,000 and $5,000 \mathrm{nM}$ ) on the thymidine incorporation into PASMCs derived from healthy rats (online supplementary fig. 1). In PASMCs derived from MCT-injected rats, there was a tendency towards reduction in the thymidine incorporation by fasudil and Y-27632 at their higher concentrations; however, the reduction was significant by $5,000 \mathrm{nM}$ of $\mathrm{Y}-27632$ ( $\mathrm{p}<0.05$ versus FCS control; fig. $1 \mathrm{~b}$ and $\mathrm{c}$ ). Azaindole- 1 reduced the thymidine incorporation significantly at all concentrations tested $(\mathrm{p}<0.05$ versus FCS control; fig. 1d). We did not observe cytotoxic effects of all the ROCK inhibitors at the concentrations tested in our study, as determined by MTT assay (online supplementary fig. 2). The findings suggest that azaindole- 1 has potent inhibitory effect on PASMC proliferation.
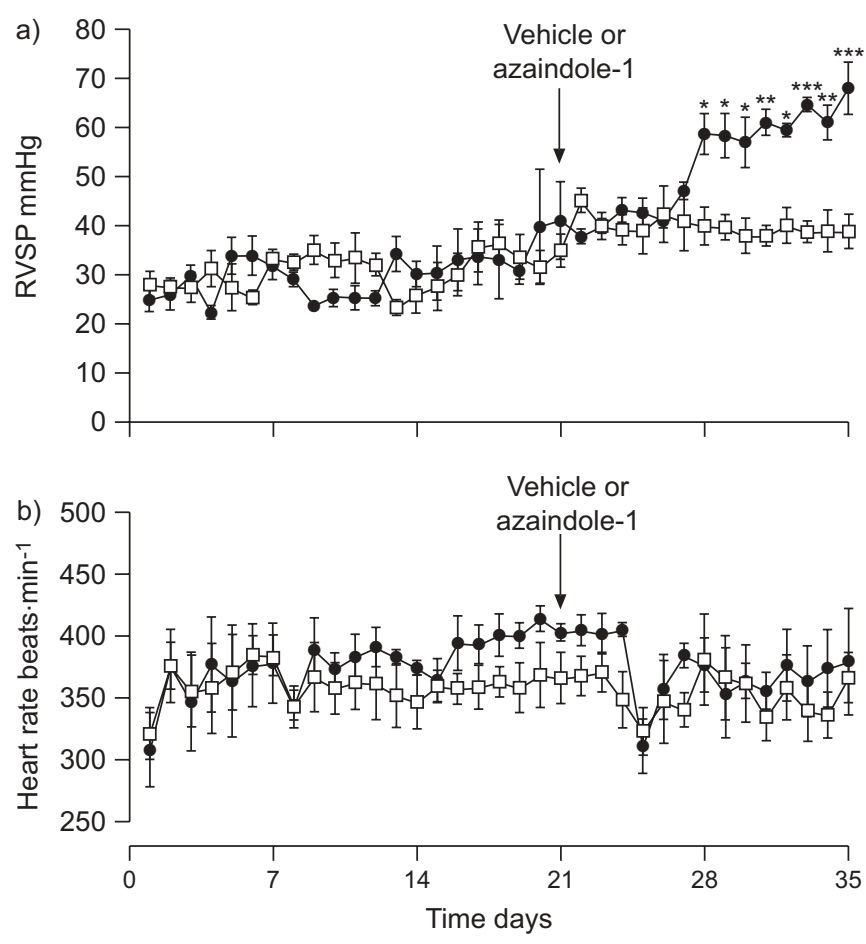

FIGURE 2. Effect of azaindole-1 on progressive elevation of right ventricular systolic pressure (RVSP). The effects of azaindole-1 on progressive increase of RVSP induced by monocrotaline (MCT) injection in rats were investigated by radiotelemetry technique and RVSP and heart rate were monitored online, as described in the Methods section. a) RVSP and b) heart rate are given. $\mathbf{0}$ : MCT-placebo; $\square$ : MCT-azaindole-1. Data are presented as mean \pm SEM $(n=6) . *$ : $p<0.05$ $\star *: p<0.01 ; * * *: p<0.001$.

\section{Effect of azaindole-1 on MCT-induced progressive elevation of RVSP}

In order to investigate the in vivo efficacy, progressive elevation of RVSP was monitored online by telemetry technique in MCTinjected rats treated with azaindole- 1 . The RVSP at day 1 $(26.5 \pm 1.7 \mathrm{mmHg})$ was significantly elevated at day 21 $(37.8 \pm 0.9 \mathrm{mmHg})$ and further at day $35(67.9 \pm 4.3 \mathrm{mmHg})$ in rats receiving placebo (fig. 2a). Treatment with azaindole-1 daily from day 21 to 35 significantly reduced RVSP $(38.8 \pm 2.9 \mathrm{mmHg}$ at day 35$)$. To check if azaindole- 1 induced any reflex tachycardia, we monitored the heart rate of the rats. We observed that the heart rates of placebo and azaindole-1 treated rats were comparable (fig. $2 b$ ). The findings suggest that azaindole-1 has potent pulmonary vasorelaxant effect in vivo.

\section{Effects of azaindole-1 on haemodynamics in MCT- and chronic hypoxia-induced $\mathbf{P H}$}

We investigated the therapeutic efficacy of azaindole- 1 in two independent animal models of $\mathrm{PH}$, as described in the Methods section. MCT induced $\mathrm{PH}$ in rats receiving placebo as reflected by the significant increase of RVSP $(72.3 \pm 2.6$ versus $27.2 \pm$ $1.3 \mathrm{mmHg}$ in healthy control) at day 35 of MCT injection (fig. 3a). Treatment with azaindole-1 resulted in a significant decrease of RVSP $(49.5 \pm 3.7 \mathrm{mmHg})$ compared with the placebo rats. TPR was significantly increased in rats receiving placebo $\left(2.96 \pm 0.24 \mathrm{mmHg} \cdot \mathrm{min} \cdot \mathrm{mL}^{-1}\right.$ per $100 \mathrm{~g}$ body weight $)$ compared 

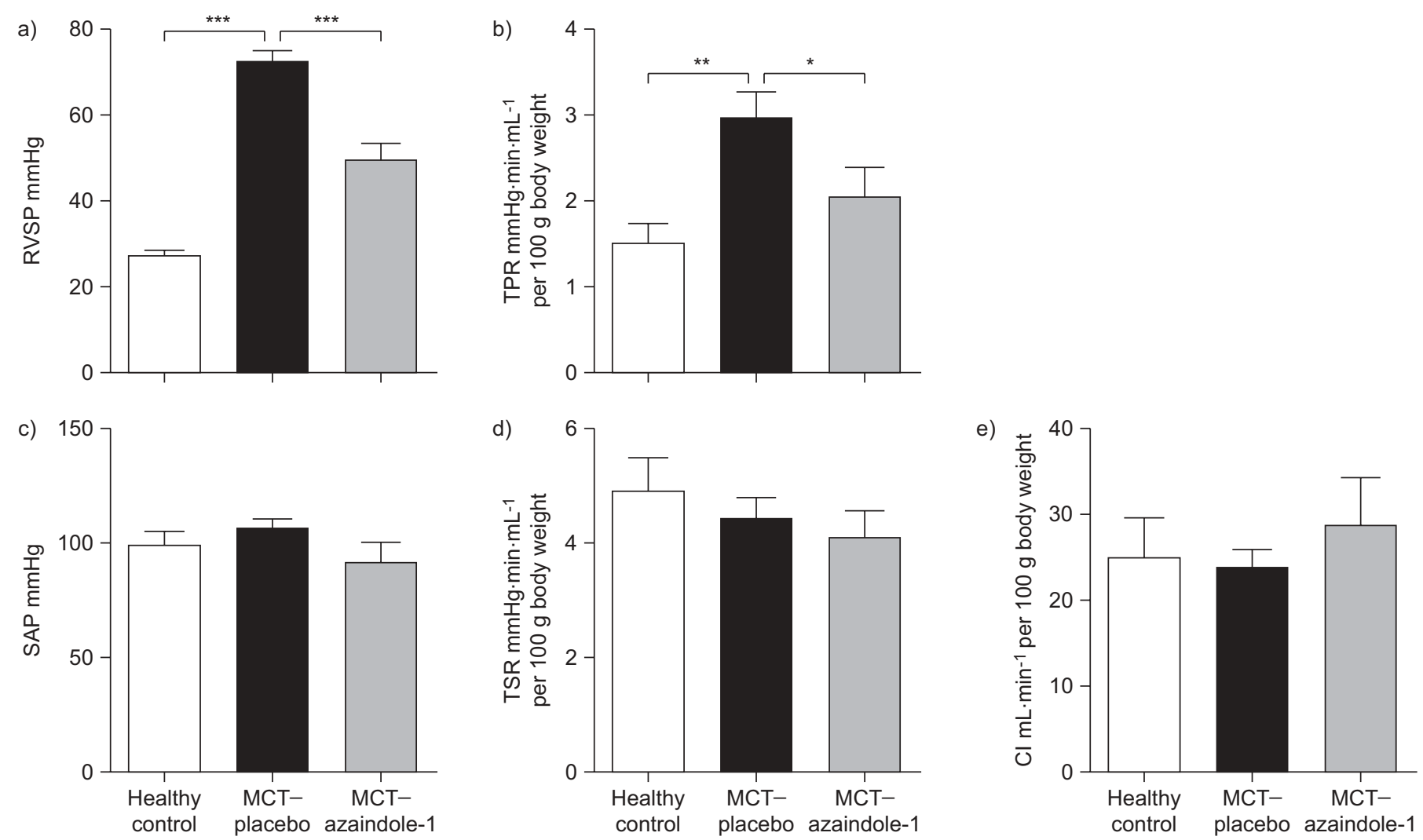

FIGURE 3. Effect of azaindole-1 on haemodynamics in monocrotaline (MCT)-induced pulmonary hypertension in rats. Rats were injected with saline (healthy controls) or MCT. The MCT-injected rats were treated with azaindole-1 or placebo from day 21 to 35 after MCT injection, followed by haemodynamic measurement at day 35 , as described in the Methods section. a) Right ventricular systolic pressure (RVSP), b) total pulmonary resistance (TPR), c) systemic arterial pressure (SAP), d) total systemic resistance (TSR) and e) cardiac index $(\mathrm{Cl})$ of different experimental groups are given. Data are presented as mean \pm SEM $(n=10-15)$. *: $p<0.05 ; * \star: p<0.01 ; * \star *: p<0.001$.

with the healthy control $\left(1.51 \pm 0.15 \mathrm{mmHg} \cdot \mathrm{min} \cdot \mathrm{mL}^{-1}\right.$ per $100 \mathrm{~g}$ body weight) and azaindole-1 treatment reduced the TPR $\left(2.04 \pm 0.22 \mathrm{mmHg} \cdot \mathrm{min} \cdot \mathrm{mL}^{-1}\right.$ per $100 \mathrm{~g}$ body weight; $\mathrm{p}<0.05$ versus placebo) (fig. 3b). There was no significant change in SAP and TSR among the experimental groups (fig. $3 \mathrm{c}$ and d). In addition, analysis of cardiac output showed a comparable cardiac index among the experimental groups (24.9 \pm 4.2 , $23.8 \pm 1.9$ and $28.8 \pm 3.5 \mathrm{~mL} \cdot \mathrm{min}^{-1}$ per $100 \mathrm{~g}$ body weight for healthy controls, MCT-placebo- and azaindole-1-treated rats respectively) (fig. 3e).

Chronic hypoxia induced $\mathrm{PH}$ in mice receiving placebo as reflected by significant increase in RVSP $(33.3 \pm 1.2$ versus $23.3 \pm 1.1 \mathrm{mmHg}$ under normoxia) (fig. 4a). Treatment with azaindole- 1 significantly decreased RVSP $(26.7 \pm 0.8 \mathrm{mmHg})$ compared with the hypoxic placebo mice. Hypoxic mice tended to have slightly decreased SAP; however, no significant difference was observed in SAP between placebo- and azaindole-1-treated mice $(68.1 \pm 1.7$ and $61.0 \pm 3.5 \mathrm{mmHg}$, respectively) (fig. 4b). There was no significant effect on body weight of the animals associated with azaindole- 1 treatment (online supplementary fig. 3).

\section{Effects of azaindole-1 on RVH in MCT- and chronic hypoxia- induced $\mathrm{PH}$}

We investigated $\mathrm{RVH}$ by measuring the $\mathrm{RV} /(\mathrm{LV}+\mathrm{S})$ ratio and found that the increased RVSP was accompanied by RVH in both MCT- and chronic hypoxia-induced PH. The RV/(LV+S) ratio was significantly increased in MCT-injected rats receiving placebo $(0.48 \pm 0.01)$ compared with the healthy rats $(0.22 \pm$ $0.01)$. Treatment with azaindole-1 significantly reduced the $\mathrm{RV} /(\mathrm{LV}+\mathrm{S})$ ratio $(0.38 \pm 0.02$ versus placebo) (fig. $5 \mathrm{a})$. Mice under chronic hypoxia revealed significantly higher RV/ $(\mathrm{LV}+\mathrm{S})$ ratio $(0.34 \pm 0.01)$ compared with the normoxic mice $(0.24 \pm 0.01)$. Treatment with azaindole- 1 improved the chronic hypoxia-induced $\mathrm{RVH}$ as reflected by significantly reduced $\mathrm{RV} /(\mathrm{LV}+\mathrm{S})$ ratio $(0.310 \pm 0.001)$ (fig. $5 \mathrm{~b})$.

\section{Effects of azaindole-1 on vascular remodelling in MCT- and chronic hypoxia-induced $\mathbf{P H}$}

The effects of azaindole- 1 on pulmonary vascular remodelling were assessed by determining the degree of muscularisation and medial wall thickness of the peripheral pulmonary arteries. MCT injection in rats and chronic hypoxia in mice resulted in an enhanced pulmonary artery muscularisation as evident from the enhanced immunoreactivity for $\alpha$-smooth muscle cell actin (figs $6 \mathrm{a}-\mathrm{c}$ and $7 \mathrm{a}-\mathrm{c}$ ). Pulmonary vascular morphometry revealed significantly increased fully muscularised vessels $(57.0 \pm 1.5 \%)$ and decreased nonmuscularised vessels $(2.4 \pm 0.3 \%)$ in $\mathrm{MCT}$-injected rats receiving placebo compared with healthy controls $(2.2 \pm 0.8 \%$ and $42.2 \pm 3.7 \%$, respectively). Azaindole-1 treatment significantly decreased fully muscularised vessels $(18.5 \pm 2.4 \%)$ (fig. $6 \mathrm{~d})$. There was significantly higher proportion of partially muscularised 

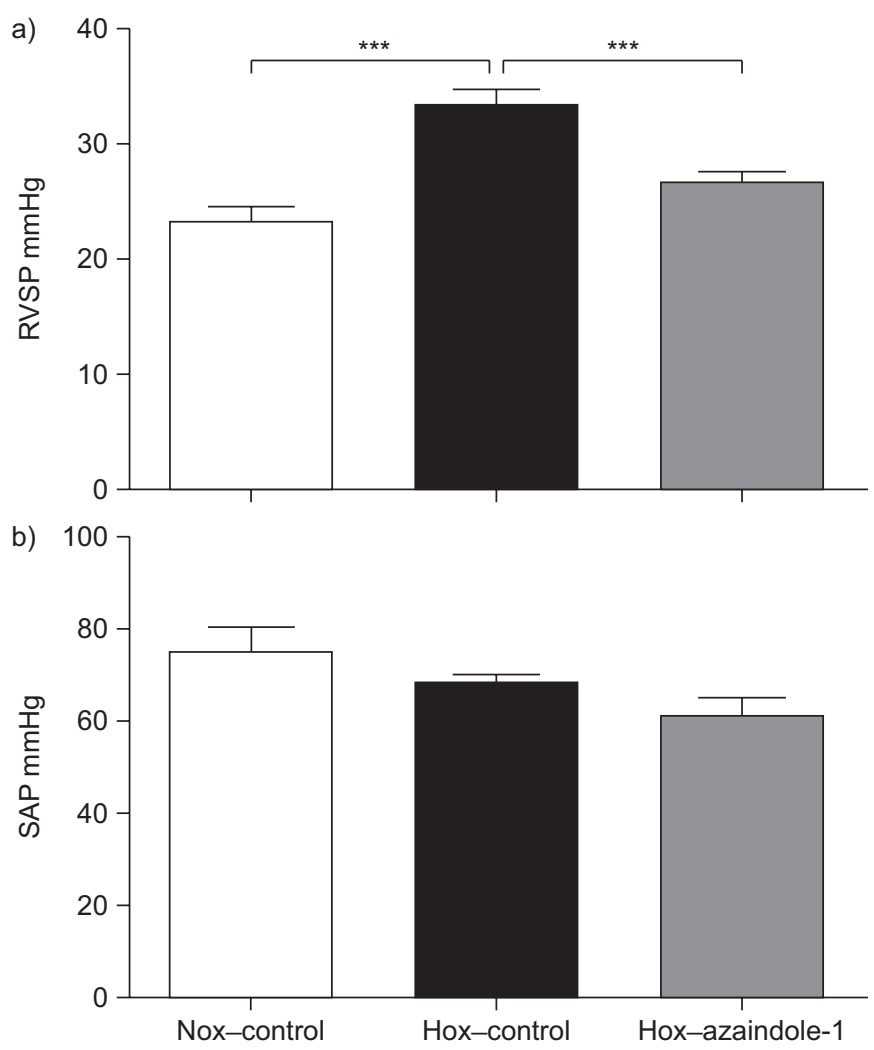

FIGURE 4. Effect of azaindole-1 on haemodynamics in chronic hypoxiainduced pulmonary hypertension in mice. Mice were exposed to normoxia (Nox) or chronic hypoxia (Hox). Hypoxic mice were treated with azaindole-1 or placebo and haemodynamic measurement was done at day 35 , as described in the Methods section. a) Right ventricular systolic pressure (RVSP) and b) systemic arterial pressure (SAP) of different experimental groups are given. Data are presented as mean $\pm \operatorname{SEM}(n=6-10) .{ }^{* * *}: p<0.001$.

vessels in azaindole-1-treated rats $(73.3 \pm 2.2 \%$ versus $40.6 \pm$ $1.4 \%$ in placebo), suggesting that the treatment impaired the progressive muscularisation by preventing the shift from partial towards full muscularisation of the vessels. Moreover, we measured the medial wall thickness of the same size vessels. There was significantly increased medial wall thickness in placebo $(22.3 \pm 0.9 \%$ versus $9.7 \pm 0.4 \%$ in healthy controls). Corroborating the decreased fully muscularised vessels, azaindole-1 significantly reduced the medial wall thickness $(14.0 \pm 0.6 \%)$ (fig. $6 \mathrm{e}-\mathrm{h})$.

In chronic hypoxic mice, the nonmuscularised vessels were significantly decreased $(4.9 \pm 1.5 \%$ versus $49.3 \pm 1.3 \%$ in normoxic mice), whereas the partially and fully muscularised vessels were significantly increased $(63.5 \pm 4.7 \%$ and $31.5 \pm 3.9 \%$ versus $47.3 \pm 0.5 \%$ and $3.5 \pm 1.3 \%$ in normoxic mice, respectively). Treatment with azaindole-1 resulted in significant reduction of fully muscularised vessels $(7.5 \pm 1.7 \%)$ (fig. 7d). As was observed in MCT-injected rats, the proportion of partially muscularised arteries was higher in mice receiving azaindole-1 $(80.9 \pm 2.9 \%)$. Chronic hypoxia resulted in significantly increased medial wall thickness $(17.8 \pm 0.9 \%)$ compared with the normoxic control mice $(10.1 \pm 0.3 \%$ ) (fig. 7e-h). Corroborating the decrease in fully muscularised vessels,
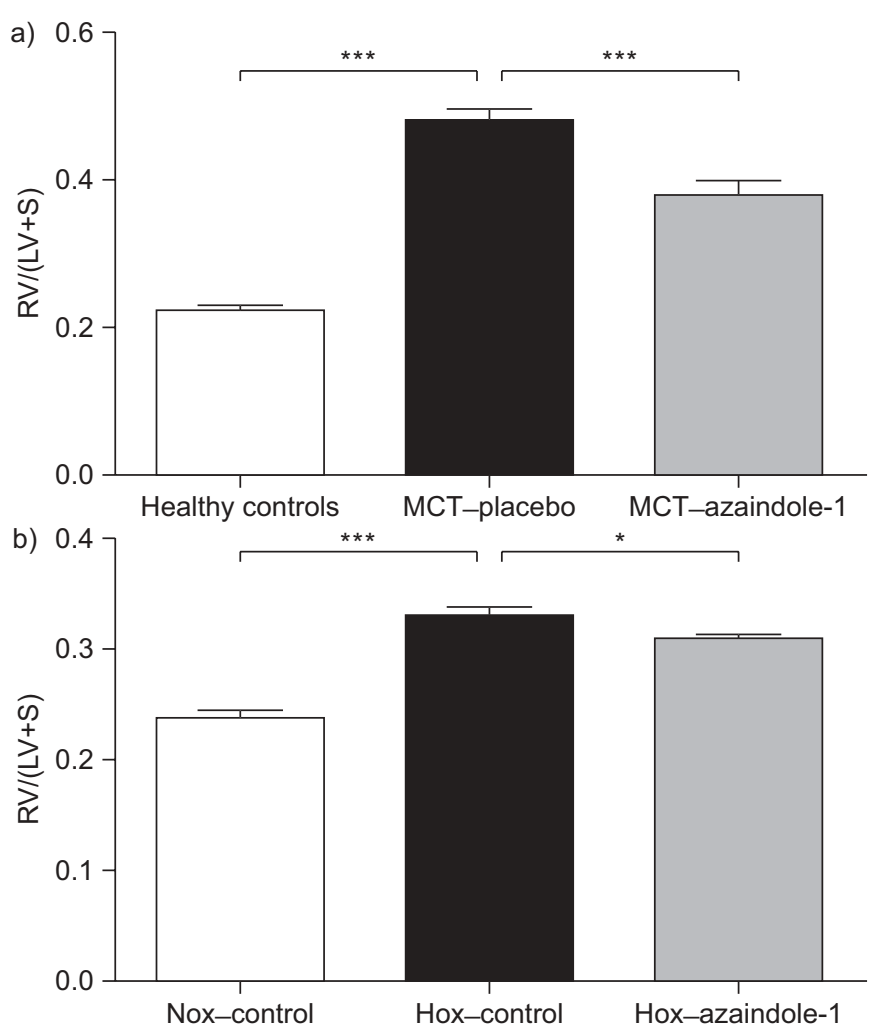

FIGURE 5. Effect of azaindole-1 on right ventricular hypertrophy in monocrotaline (MCT)- and chronic hypoxia-induced pulmonary hypertension. Rats were injected with saline (healthy control) or MCT. Mice were exposed to normoxia (Nox) and chronic hypoxia (Hox). The MCT-injected rats and hypoxic mice were treated with azaindole-1 or placebo from day 21 for 2 weeks, followed by haemodynamic and right ventricular hypertrophy measurements at day 35, as described in the Methods section. Right to left ventricular plus septum weight ratio $(R V /(L V+S))$ of a) MCT-injected rats $(n=10-15)$ and b) hypoxic mice $(n=6-10)$ are given. Data are presented as mean \pm SEM. *: $p<0.05 ; * * *: p<0.001$.

the medial wall thickness was significantly reduced in azaindole-1-treated mice (12.4 $\pm 0.4 \%$ ) (fig. $7 \mathrm{~h}$ ).

\section{Effects of azaindole-1 on ROCK activity and pulmonary vascular cell proliferation}

We investigated the effects of azaindole- 1 on ROCK activity by employing immunohistochemistry for p-MYPT1. The immunoreactivity was localised in the media of the vessels and was enhanced in the lung tissues of MCT-injected rats receiving placebo. There was decreased immunoreactivity in MCTinjected rats treated with azaindole-1 (fig. 8a).

To confirm if the observed in vitro effect of azaindole- 1 on cell proliferation was also present in vivo, we performed immunostaining for PCNA. We observed that immunoreactivity for PCNA was significantly increased in lung tissues from MCTinjected rats compared with that in healthy control rats (fig. 8d-f). We analysed the same size vessels as was used for vascular morphometry to quantify the PCNA-positive vascular cells and express the result as IOP. The findings revealed that there was higher IOP in MCT-injected rats receiving placebo $(431.9 \pm 7.2 \%$ versus $100.0 \pm 25.8 \%$ in healthy control rats) (fig. 8g). Corroborating the in vitro data, the IOP 

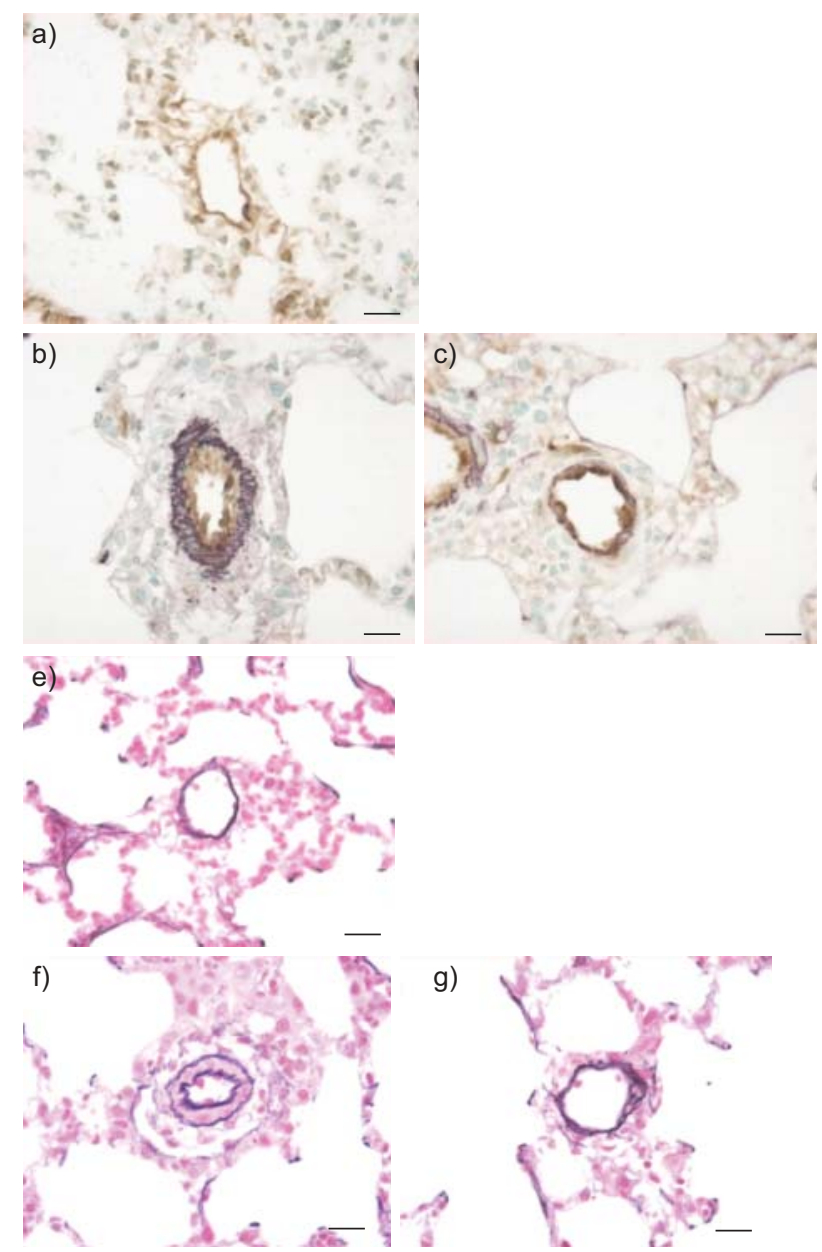

g)

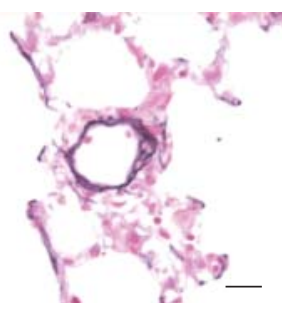

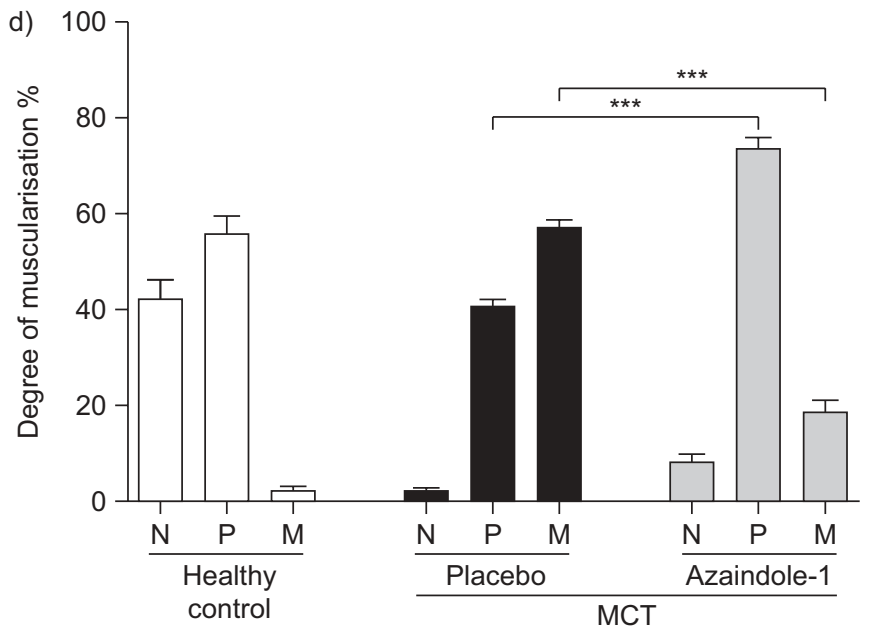

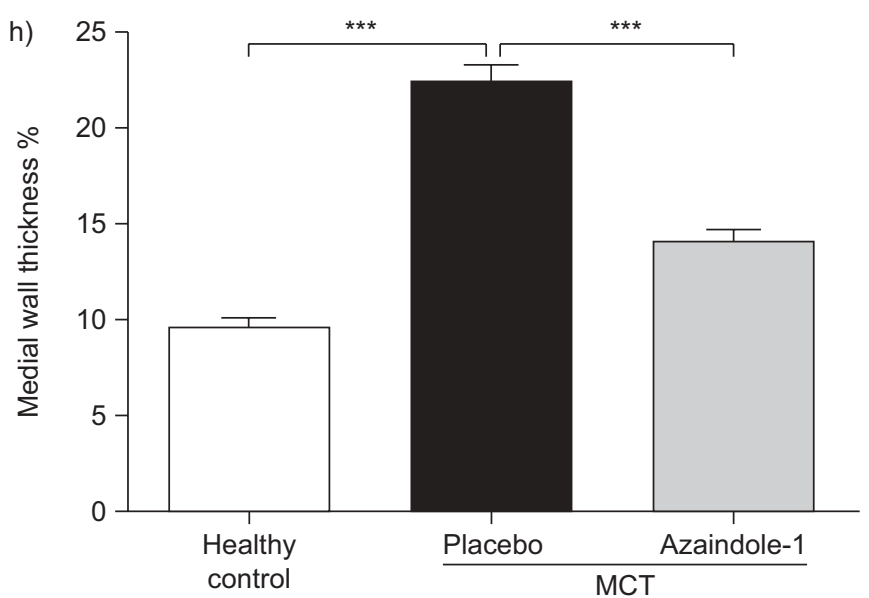

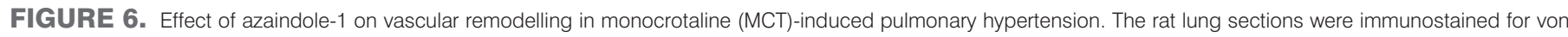

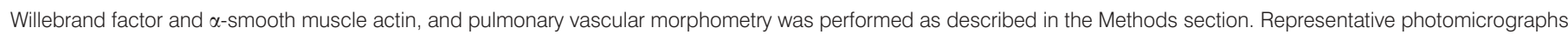

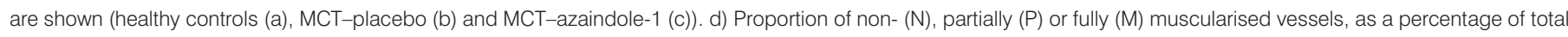

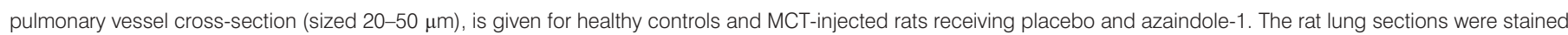

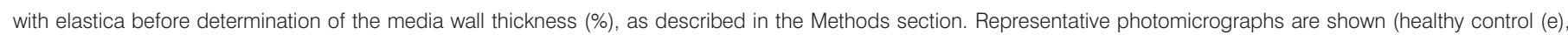

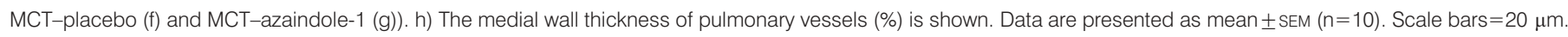
$\star \star *: p<0.001$.

was significantly reduced in MCT-injected rats receiving azaindole-1 (184.1 $\pm 10.9 \%$ ) (fig. $8 \mathrm{~g}$ ).

\section{DISCUSSION}

The major findings of this study are: 1) azaindole- 1 significantly inhibited acute hypoxic pulmonary vasoconstriction $e x$ vivo and the proliferation of primary rat PASMC in vitro; 2) azaindole-1 treatment significantly improved haemodynamics, $\mathrm{RVH}$ and pulmonary vascular remodelling in MCT-injected rats and chronically hypoxic mice; and 3) the improvement in haemodynamics and vascular remodelling in rats was accompanied by an impaired ROCK activity and a decrease in proliferating cells in pulmonary vessels, as evident from reduced immunoreactivity for $\mathrm{p}-\mathrm{MYPT} 1$ and PCNA.

Exploring promising targets and developing effective therapeutic approaches for $\mathrm{PH}$ has been an actively pursued research focus over the past years. As a consequence, prolonged survival of the patients and improvements in their quality of life have been achieved with the therapeutic options available for $\mathrm{PH}$, such as endothelin receptor inhibitors, prostacyclin and PDE5 inhibitors, and other therapeutic approaches are under clinical investigation $[35,36]$.

The role of ROCK signalling in cardiovascular physiology and pathophysiology is rapidly unfolding in the recent years and the ROCK inhibitors, fasudil and Y-27632, have served as a useful tool [8]. Recently, KAST et al. [28] reported a novel ROCK inhibitor azaindole- 1 that dose-dependently inhibited human ROCK-1 and ROCK-2 in a low nanomolar range with $\mathrm{IC}_{50}$ values of $0.6 \mathrm{nM}$ and $1.1 \mathrm{nM}$, respectively [28]. Azaindole-1 is more potent than fasudil and Y-27632, which have $\mathrm{IC}_{50}$ values of 158 and $162 \mathrm{nM}$, respectively, for ROCK-2 [37]. In addition, azaindole-1 in a nanomolar range inhibits the phenylephrineinduced contraction of rabbit saphenous artery in a concentration-dependent manner [28]. In agreement with previous data, we found that azaindole- 1 ( $\mathrm{IC}_{50}$ of $79.2 \mathrm{nM}$ ) potently inhibited phenylephrine-induced contraction of the 

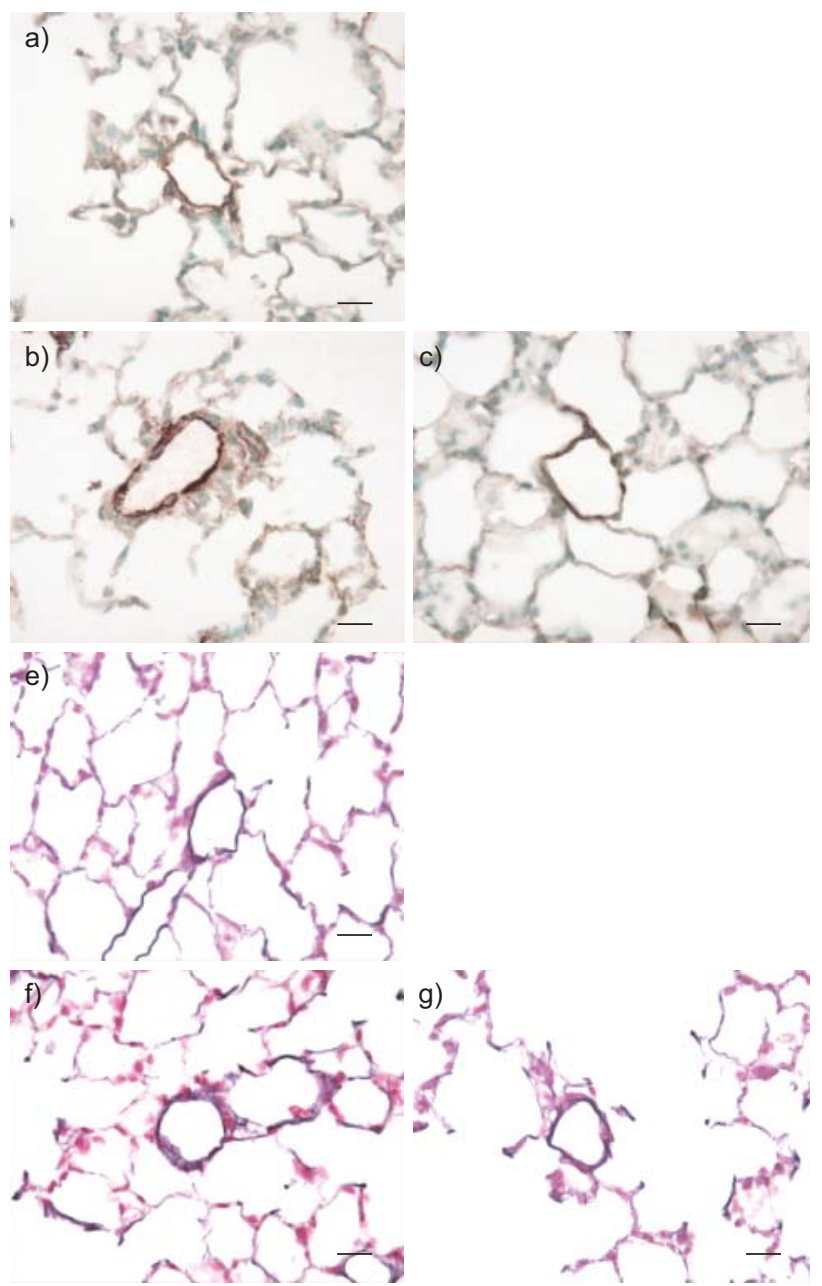
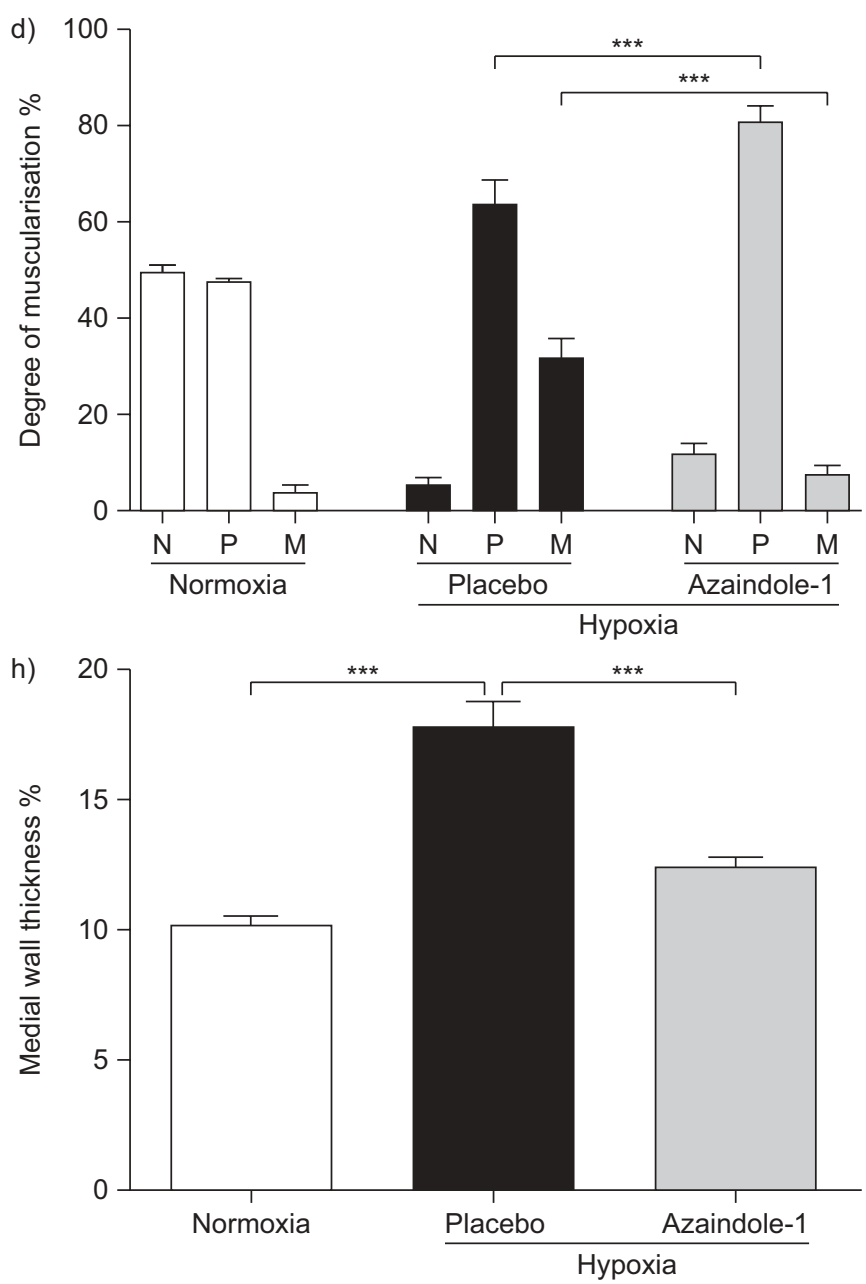

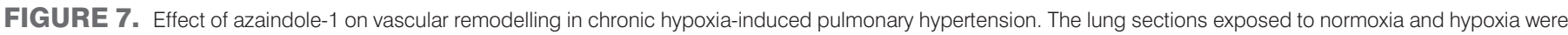

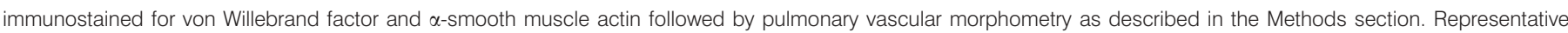

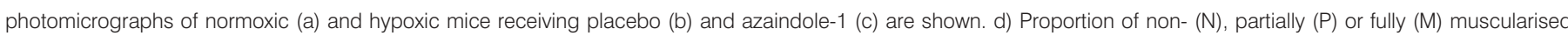

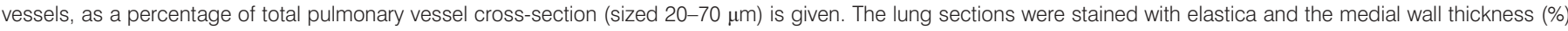

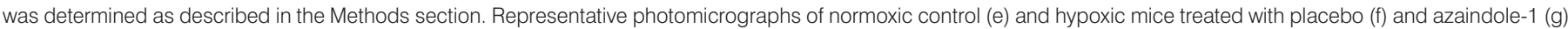
are given. $h$ ) The medial wall thickness (\%) of pulmonary vessels is shown. Data are presented as mean \pm SEM $(n=6-10) . S c a l e$ bars $=20 \mu m$. $* \star *: p<0.001$.

rabbit saphenous artery compared with fasudil and Y-27632 ( $\mathrm{IC}_{50}$ of 9,313 and $793 \mathrm{nM}$, respectively) (data not shown). Extending the findings, we showed in the current study that azaindole-1 significantly inhibited acute hypoxic pulmonary vasoconstriction in isolated, ventilated and buffer-perfused murine lungs. Moreover, we observed that effect of azaindole was more potent than fasudil and Y-27632. Taken together, the data suggest that azaindole- 1 is not only a highly selective and potent inhibitor of ROCK but is also a stronger vasorelaxant than fasudil and Y-27632.

It is well established that hyperactivation of ROCK, by inhibiting myosin phosphatase activity and increasing myosin light chain phosphorylation, leads to contraction of vascular smooth muscle cells and, thus, to vasoconstriction [4, 38]. In experimental $\mathrm{PH}$, acute inhibition of ROCK has been demonstrated to result in pulmonary vasorelaxation and, thus, reduced pulmonary arterial pressure [14, 16, 39]. In this line, we observed that azaindole-1 significantly impaired the MCTinduced progressive elevation of RVSP in rats as monitored online via radio-telemetry. However, no significant effect was observed on heart rates, suggesting that azaindole-1 treatment did not result in reflex tachycardia. Our finding is in agreement with the studies that describe the involvement of ROCK-mediated sustained vasoconstriction in the $\mathrm{PH}$ pathogenesis [14, 39-41]. Moreover, as inhibition of ROCK has been shown to impair pulmonary vascular remodelling [10, 42-44], we sought to test the response of proliferating PASMCs to azaindole-1 in vitro. We observed that azaindole- 1 significantly inhibited the thymidine incorporation into primary rat PASMCs at high nanomolar to low micromolar range, and the effect was more potent than that of fasudil and Y-27632. Taken together, the findings of our in vivo, ex vivo and in vitro studies attribute potent vasorelaxant and antiproliferative properties to azaindole- 1 and, thus, substantiate its therapeutic potential in $\mathrm{PH}$.

Therefore, we performed the chronic treatment studies and investigated the therapeutic efficacy of azaindole- 1 in experimental $\mathrm{PH}$ induced by MCT injection in rats and by chronic 

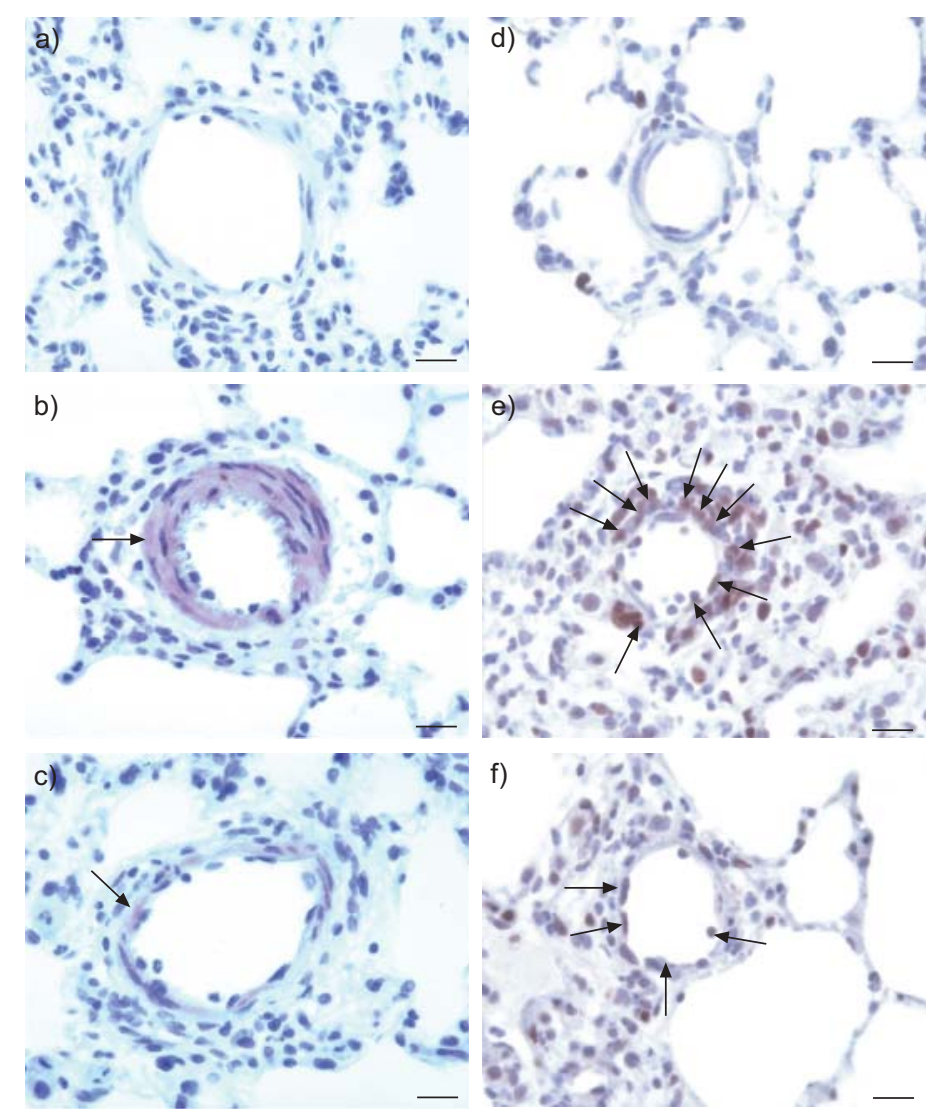

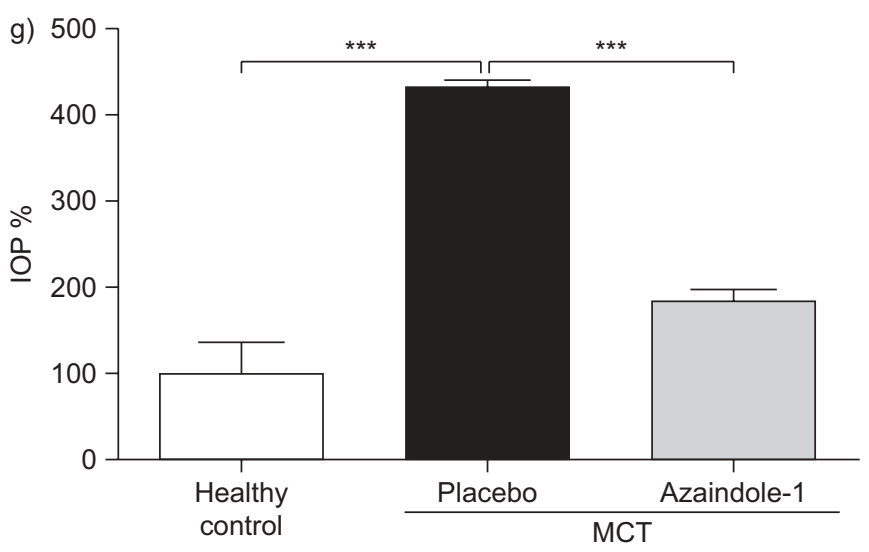

FIGURE 8. Effects of azaindole-1 on Rho kinase (ROCK) activity and pulmonary vascular cell proliferation. The ROCK activity and pulmonary vascular cell proliferation were investigated in the rat lung sections by immunostaining phospho-myosin phosphatase target subunit 1 (p-MYPT1) and proliferating cell nuclear antigen (PCNA), respectively, as described in the Methods section. Representative photomicrographs of p-MYPT1 (a-c) and PCNA (d-f) staining (healthy controls ( $a$ and d), monocrotaline (MCT)-placebo (b and e) and MCTazaindole-1 (c and f)) are shown. The PCNA-positive vascular cells were counted and the index of proliferation (IOP) was calculated as described in the Methods section. g) IOP (\%) for healthy controls, MCT-placebo and MCTazaindole- 1 is given. Data are presented as mean \pm SEM $(n=6-8)$. Positive immunoreactivity is indicated by an arrow (reddish-brown staining); scale bars $=20 \mu \mathrm{m} . * * *: \mathrm{p}<0.001$ hypoxia in mice. We found that azaindole-1 improved $\mathrm{PH}$, $\mathrm{RVH}$ and pulmonary vascular remodelling as evident from significantly reduced RVSP, TPR and RV/(LV+S), and muscularisation and medial wall thickness of peripheral pulmonary vessels. Moreover, the SAP did not change significantly in the treated animals. Although at first glance it seems contradictory to the findings by KAST et al. [28], who observed reduction of blood pressure in spontaneously hypertensive rats receiving azaindole-1. However, the discrepancy could be explained at least in part by the differences in animal models and duration of treatment. In spontaneously hypertensive rats, the ROCK activity is enhanced in the systemic vasculature [45]; furthermore, KAST et al. [28] treated the normotensive rats only once and spontaneously hypertensive rats for 4 days, and noted in the spontaneously hypertensive rats that the blood pressure lowering effect was gradually decreasing. In the current study, we used different animal models of $\mathrm{PH}$ and treated the animals for 2 weeks. Our data, therefore, may not be directly comparable to that of KAST et al. [28]. Notably, the sustained pulmonary ROCK activation in animal models of $\mathrm{PH}$ [9] may underlie the pulmonary specific effects of selective ROCK inhibitors. An accumulating body of literature describes beneficial effects of ROCK inhibition on the development of MCT- and chronic hypoxia-induced PH in rodents [11, 15, 42, 44, 46-48]; our results extend these findings, demonstrating that azaindole- 1 is beneficial even when the treatment commences at the time the disease is already rapidly progressing. Moreover, we found that azaindole- 1 treatment resulted in an impairment of ROCK activity, as determined by a reduction in p-MYPT1 immunoreactivity, and a diminution of proliferating pulmonary vascular cells, as determined by PCNA staining. Taken together, our data suggest that the therapeutic efficacy of ROCK inhibition by azaindole- 1 may be associated with its vasorelaxant and antiproliferative potency. In this line, ABE et al. [10] have reported an improvement of MCT-induced PH in rats by long-term treatment with fasudil. However, despite the fact that fasudil shows therapeutic efficacy, OKA et al. [9] have discussed, in their recent review, the discrepancy in the findings depending on the dose, route of administration and animal models of PH. Fasudil has been used in previous studies at the dose range of 30-100 mg per kg body weight, whereas azaindole- 1 shows the therapeutic benefit at considerably lower dose of $10 \mathrm{mg}$ per $\mathrm{kg}$ body weight, suggesting that not only the in vitro but also the in vivo effects of azaindole- 1 are potent. Our findings indicate that the therapeutic efficacy of azaindole- 1 is independent of the cause of the disease. This may be attributable to the involvement of ROCK in the pathogenesis of experimental $\mathrm{PH}$ induced by different stimuli $[10,13,15,16]$. Moreover, ROCK signalling is implicated in the beneficial effects of therapeutic approaches targeting signalling cascades other than ROCK $[12,13,19,47-$ 49]. It seems likely, therefore, that ROCK may be the convergent point for various signalling cascades implicated in the pathogenesis of $\mathrm{PH}$.

MCT-induced $\mathrm{PH}$ in rats and chronic hypoxia-induced $\mathrm{PH}$ in mice share many features of clinical $\mathrm{PH}$ and are well accepted animal models for the investigation of the pathomechanism and therapeutics of $\mathrm{PH}$; however, they are not without shortcomings with regard to mimicking human $\mathrm{PH}$ pathology. Extensive studies on various animal models in recent years 
have resulted in the discovery of promising therapeutic targets, including ROCK [35]. Moreover, activation of ROCK has been demonstrated in animal models of severe $\mathrm{PH}$ characterised by the presence of occlusive pulmonary vascular lesions [13, 16]. Azaindole-1 can thus be anticipated to yield therapeutic benefit; however, studies are warranted to investigate if the antiproliferative and vasorelaxant potency of azaindole- 1 is adequate for improvement of the severely remodelled pulmonary vessels with occlusive lesions that are commonly observed in human PH. Regarding human $\mathrm{PH}$, literature is emerging that implicates ROCK signalling in the disease pathogenesis and, thus, this signalling pathway represents a potential therapeutic target [17, 19, 21, 23]. Moreover, acute inhibition of ROCK by fasudil has revealed beneficial effects, as evident from reduction of pulmonary vascular resistance and pulmonary arterial pressure in patients with severe $\mathrm{PH}[17,18,20,22]$. The data thus support that inhibition of ROCK with a potent and highly selective inhibitor may offer a potential therapeutic strategy.

In summary, we demonstrate that daily oral application of azaindole-1 improves the haemodynamics, RVH and pulmonary vascular remodelling in experimental $\mathrm{PH}$. This study, to our knowledge, is the first to investigate the therapeutic efficacy of a novel potent and orally available ROCK inhibitor, azaindole-1, in two independent animal models of PH. Moreover, we show that azaindole-1 potently inhibits hypoxic pulmonary vasoconstriction in isolated, ventilated and buffer-perfused murine lungs, significantly inhibits proliferation of primary rat PASMCs in vitro and reduces the number of proliferating pulmonary vascular cells in MCT-injected rats, suggesting that the therapeutic benefit of azaindole- 1 may be associated with its vasorelaxant and antiproliferative potency. Taken together, the findings suggest that azaindole-1 may represent a novel therapeutic approach for the treatment of $\mathrm{PH}$.

\section{STATEMENT OF INTEREST}

Statements of interest for R. Kast, H. Schirok, J-P. Stasch, N. Weissmann, F. Grimminger, W. Seeger and R.T. Schermuly can be found at www.erj.ersjournals.com/misc/statements.dtl

\section{REFERENCES}

1 Humbert M, Morrell NW, Archer SL, et al. Cellular and molecular pathobiology of pulmonary arterial hypertension. J Am Coll Cardiol 2004; 43: Suppl. S, 13S-24S.

2 Morrell NW, Adnot S, Archer SL, et al. Cellular and molecular basis of pulmonary arterial hypertension. J Am Coll Cardiol 2009; 54: Suppl., S20-S31.

3 Ghofrani HA, Barst RJ, Benza RL, et al. Future perspectives for the treatment of pulmonary arterial hypertension. J Am Coll Cardiol 2009; 54: Suppl., S108-S117.

4 Etienne-Manneville S, Hall A. Rho GTPases in cell biology. Nature 2002; 420: 629-635.

5 Leung T, Manser E, Tan L, et al. A novel serine/threonine kinase binding the Ras-related RhoA GTPase which translocates the kinase to peripheral membranes. J Biol Chem 1995; 270: 29051-29054.

6 Matsui T, Amano M, Yamamoto T, et al. Rho-associated kinase, a novel serine/threonine kinase, as a putative target for small GTP binding protein Rho. EMBO J 1996; 15: 2208-2216.

7 Nakagawa O, Fujisawa K, Ishizaki T, et al. ROCK-I and ROCK-II, two isoforms of Rho-associated coiled-coil forming protein serine/ threonine kinase in mice. FEBS Lett 1996; 392: 189-193.
8 Loirand G, Guerin P, Pacaud P. Rho kinases in cardiovascular physiology and pathophysiology. Circ Res 2006; 98: 322-334.

9 Oka M, Fagan KA, Jones PL, et al. Therapeutic potential of RhoA/ Rho kinase inhibitors in pulmonary hypertension. $\mathrm{Br} J$ Pharmacol 2008; 155: 444-454.

10 Abe K, Shimokawa H, Morikawa K, et al. Long-term treatment with a Rho-kinase inhibitor improves monocrotaline-induced fatal pulmonary hypertension in rats. Circ Res 2004; 94: 385-393.

11 Abe K, Tawara S, Oi K, et al. Long-term inhibition of Rho-kinase ameliorates hypoxia-induced pulmonary hypertension in mice. J Cardiovasc Pharmacol 2006; 48: 280-285.

12 Hemnes AR, Zaiman A, Champion HC. PDE5A inhibition attenuates bleomycin-induced pulmonary fibrosis and pulmonary hypertension through inhibition of ROS generation and RhoA/ Rho kinase activation. Am J Physiol Lung Cell Mol Physiol 2008; 294: L24-L33.

13 Homma N, Nagaoka T, Karoor V, et al. Involvement of RhoA/ Rho kinase signaling in protection against monocrotaline-induced pulmonary hypertension in pneumonectomized rats by dehydroepiandrosterone. Am J Physiol Lung Cell Mol Physiol 2008; 295: L71-L78.

14 McNamara PJ, Murthy P, Kantores C, et al. Acute vasodilator effects of Rho-kinase inhibitors in neonatal rats with pulmonary hypertension unresponsive to nitric oxide. Am J Physiol Lung Cell Mol Physiol 2008; 294: L205-L213.

15 Nagaoka T, Gebb SA, Karoor V, et al. Involvement of RhoA/Rho kinase signaling in pulmonary hypertension of the fawn-hooded rat. J Appl Physiol 2006; 100: 996-1002.

16 Oka M, Homma N, Taraseviciene-Stewart L, et al. Rho kinasemediated vasoconstriction is important in severe occlusive pulmonary arterial hypertension in rats. Circ Res 2007; 100: 923-929.

17 Do EZ, Fukumoto Y, Takaki A, et al. Evidence for Rho-kinase activation in patients with pulmonary arterial hypertension. Circ J 2009; 73: 1731-1739.

18 Fukumoto Y, Matoba T, Ito A, et al. Acute vasodilator effects of a Rho-kinase inhibitor, fasudil, in patients with severe pulmonary hypertension. Heart 2005; 91: 391-392.

19 Guilluy C, Eddahibi S, Agard C, et al. RhoA and Rho kinase activation in human pulmonary hypertension: role of 5-HT signaling. Am J Respir Crit Care Med 2009; 179: 1151-1158.

20 Ishikura K, Yamada N, Ito M, et al. Beneficial acute effects of Rhokinase inhibitor in patients with pulmonary arterial hypertension. Circ J 2006; 70: 174-178.

21 Laumanns IP, Fink L, Wilhelm J, et al. The noncanonical WNT pathway is operative in idiopathic pulmonary arterial hypertension. Am J Respir Cell Mol Biol 2009; 40: 683-691.

22 Li F, Xia W, Yuan S, et al. Acute inhibition of Rho-kinase attenuates pulmonary hypertension in patients with congenital heart disease. Pediatr Cardiol 2009; 30: 363-366.

23 Liu $Y$, Ren W, Warburton R, et al. Serotonin induces Rho/ROCKdependent activation of Smads 1/5/8 in pulmonary artery smooth muscle cells. FASEB J 2009; 23: 2299-2306.

24 Ono-Saito N, Niki I, Hidaka H. H-Series protein kinase inhibitors and potential clinical applications. Pharmacol Ther 1999; 82: 123-131.

25 Uehata M, Ishizaki $\mathrm{T}$, Satoh $\mathrm{H}$, et al. Calcium sensitization of smooth muscle mediated by a Rho-associated protein kinase in hypertension. Nature 1997; 389: 990-994.

26 Asano T, Ikegaki I, Satoh S, et al. A protein kinase inhibitor, Fasudil (AT-877): a novel approach to signal transdcution therapy. Cardiovasc Drug Rev 1998; 16: 76-87.

27 Nagumo H, Seto M, Sakurada K, et al. HA1077, a protein kinase inhibitor, inhibits calponin phosphorylation on Ser175 in porcine coronary artery. Eur J Pharmacol 1998; 360: 257-264.

28 Kast R, Schirok H, Figueroa-Perez S, et al. Cardiovascular effects of a novel potent and highly selective azaindole-based inhibitor of Rho-kinase. Br J Pharmacol 2007; 152: 1070-1080. 
29 Schirok H, Kast R, Figueroa-Perez S, et al. Design and synthesis of potent and selective azaindole-based Rho kinase (ROCK) inhibitors. Chem Med Chem 2008; 3: 1893-1904.

30 Schermuly RT, Dony E, Ghofrani HA, et al. Reversal of experimental pulmonary hypertension by PDGF inhibition. J Clin Invest 2005; 115: 2811-2821.

31 Schermuly RT, Kreisselmeier KP, Ghofrani HA, et al. Chronic sildenafil treatment inhibits monocrotaline-induced pulmonary hypertension in rats. Am J Respir Crit Care Med 2004; 169: 39-45.

32 Schermuly RT, Pullamsetti SS, Kwapiszewska G, et al. Phosphodiesterase 1 upregulation in pulmonary arterial hypertension: target for reverse-remodeling therapy. Circulation 2007; 115: 2331-2339.

33 Dahal BK, Cornitescu T, Tretyn A, et al. Role of epidermal growth factor inhibition in experimental pulmonary hypertension. Am J Respir Crit Care Med 2010; 181: 158-167.

34 Weissmann N, Hackemack S, Dahal BK, et al. The soluble guanylate cyclase activator HMR1766 reverses hypoxia-induced experimental pulmonary hypertension in mice. Am J Physiol Lung Cell Mol Physiol 2009; 297: L658-L665.

35 Chin KM, Rubin LJ. Pulmonary arterial hypertension. J Am Coll Cardiol 2008; 51: 1527-1538.

36 Boutet K, Montani D, Jais X, et al. Review: therapeutic advances in pulmonary arterial hypertension. Ther Adv Respir Dis 2008; 2: 249-265.

37 Tamura M, Nakao H, Yoshizaki H, et al. Development of specific Rho-kinase inhibitors and their clinical application. Biochim Biophys Acta 2005; 1754: 245-252.

38 Wang $Y$, Zheng XR, Riddick N, et al. ROCK isoform regulation of myosin phosphatase and contractility in vascular smooth muscle cells. Circ Res 2009; 104: 531-540.

39 Nagaoka T, Fagan KA, Gebb SA, et al. Inhaled Rho kinase inhibitors are potent and selective vasodilators in rat pulmonary hypertension. Am J Respir Crit Care Med 2005; 171: 494-499.
40 Jiang BH, Tawara S, Abe K, et al. Acute vasodilator effect of fasudil, a Rho-kinase inhibitor, in monocrotaline-induced pulmonary hypertension in rats. J Cardiovasc Pharmacol 2007; 49: 85-89.

41 Hyvelin JM, Howell K, Nichol A, et al. Inhibition of Rho-kinase attenuates hypoxia-induced angiogenesis in the pulmonary circulation. Circ Res 2005; 97: 185-191.

42 Fagan KA, Oka M, Bauer NR, et al. Attenuation of acute hypoxic pulmonary vasoconstriction and hypoxic pulmonary hypertension in mice by inhibition of Rho-kinase. Am J Physiol Lung Cell Mol Physiol 2004; 287: L656-L664.

43 Li F, Xia W, Li A, et al. Long-term inhibition of Rho kinase with fasudil attenuates high flow induced pulmonary artery remodeling in rats. Pharmacol Res 2007; 55: 64-71.

44 Tawara S, Fukumoto Y, Shimokawa H. Effects of combined therapy with a Rho-kinase inhibitor and prostacyclin on monocrotalineinduced pulmonary hypertension in rats. J Cardiovasc Pharmacol 2007; 50: 195-200

45 Mukai Y, Shimokawa H, Matoba T, et al. Involvement of Rhokinase in hypertensive vascular disease - a novel therapeutic target in hypertension. FASEB J 2001; 15: 1062-1064.

46 Chapados R, Abe K, Ihida-Stansbury K, et al. ROCK controls matrix synthesis in vascular smooth muscle cells: coupling vasoconstriction to vascular remodeling. Circ Res 2006; 99: 837-844.

47 Girgis RE, Mozammel S, Champion HC, et al. Regression of chronic hypoxic pulmonary hypertension by simvastatin. Am J Physiol Lung Cell Mol Physiol 2007; 292: L1105-L1110.

48 Guilluy C, Sauzeau V, Rolli-Derkinderen M, et al. Inhibition of RhoA/Rho kinase pathway is involved in the beneficial effect of sildenafil on pulmonary hypertension. Br J Pharmacol 2005; 146: 1010-1018.

49 Homma N, Nagaoka T, Morio Y, et al. Endothelin-1 and serotonin are involved in activation of RhoA/Rho kinase signaling in the chronically hypoxic hypertensive rat pulmonary circulation. J Cardiovasc Pharmacol 2007; 50: 697-702. 